\title{
Client Satisfaction with Family Planning Services and Associated Factors in Tembaro District, Southern Ethiopia
}

This article was published in the following Dove Press journal: Open Access Journal of Contraception

\section{Daniel Wogu \\ Tsegaye Lolaso (D) \\ Mengistu Meskele}

School of Public Health, College of Health Science and Medicine, Wolaita Sodo University, Wolaita Sodo, Ethiopia
Correspondence: Tsegaye Lolaso Tel +25I-935-505-052

Email tlolaso7I@gmail.com
Introduction: Client satisfaction influences the use of family planning and other reproductive health services. This study aimed to assess the magnitude of client satisfaction with family service and its associated factors among reproductive-age women.

Patients and Methods: We conducted a facility-based cross-sectional study. A total of 411 clients, nested in four health facilities, were included in the analysis. Systematic sampling was employed to select study units for the exit interview. Data collection instruments for this study were pre-tested structured questionnaires. Client satisfaction was assessed using fifteen Likert-scaled question items. Each item of question has 5 points ranging from 1 (strongly disagree) to 5 (strongly agree) and, finally, mean was computed. The pre-coded data were entered into Epi Data version 4.2.0 and exported to SPSS version 25 for analysis. Logistic regression analysis was carried out to identify independently associated factors at a confidence interval of $95 \%$ and a significance level of p-value less than 0.05 .

Results: Magnitude of client satisfaction with family planning service was $46 \%$ [95\% CI: 41-50.8]. Rural residence [AOR=3.07; 95\% CI: 1.10-8.62], educational level of college and above $[\mathrm{AOR}=0.22 ; 95 \% \mathrm{CI}: 0.07-0.70]$ as compared to the educational level of primary education, waiting time of less than half an hour [AOR=7.80;95\% CI: 2.48-24.48], maintaining privacy [AOR $=7.16 ; 95 \% \mathrm{CI}: 2.89-17.69$ ], describing side effects of methods [AOR $=3.14 ; 95 \%$ CI: 1.02-9.76] were factors significantly associated with client satisfaction.

Conclusion: The overall magnitude of client satisfaction with the services was found to be low. Many of the factors that attributed to the low level of client satisfaction are modifiable. There is a need for organizing the family planning room as per standards, maintaining privacy, minimizing waiting time, and describing the side effects during the provision of service.

Keywords: client satisfaction, family planning service, Southern Ethiopia

\section{Introduction}

Rapid population growth resulting from high fertility rate and reduced mortality has become a new challenge of concern in sub-Saharan Africa (SSA). ${ }^{1}$ Family planning (FP) is the decision of individuals or couples to decide when and how many children they have and among the practical strategies that not only slow the population growth but also reduce maternity and child mortality due to outcomes of unintended pregnancies. ${ }^{2-4}$

Client satisfaction in family planning services is a crucial indicator that measures the extent to which a client is gratified with the services received from healthcare providers. It, therefore, reflects the gap between the expected service 
and the experience of the service, from the client's point of view. ${ }^{5,6}$ The satisfaction of clients is an essential component of quality and hence is expected to improve through better compliance with the service, and at the same time, satisfied clients will generate demand in the community and assist in the recruitment of new clients who can use the services. ${ }^{7}$ Client satisfaction has been recognized as an essential component in the evaluation of health-care quality. One of the factors that influences the use of family planning and other reproductive health services is client satisfaction with healthcare services. ${ }^{8,9}$

Client satisfaction is also an essential determinant of service uptake and continuation because satisfied clients are more likely to revisit the service and pass on a positive message to others and continue the use of particular family planning methods. ${ }^{5,10}$ It also signals other aspects of quality of care including structural and process issues of quality of care in FP services. It reflects the perception of healthcare consumers (FP clients) on the quality of care on existing health services. ${ }^{11}$

Studies from developing countries have found that not being satisfied with family planning services is a prime reason for high rates of discontinuation, reduced utilization of FP services, non-compliance, and high rates of unintended pregnancy. ${ }^{5,11,12}$

Evidence from several studies shows that client satisfaction is affected by different factors. Those are; sociodemographic factors: marital status, educational status, and age, ${ }^{12,13}$ service provider level factors: provision of information on potential side effects, ensuring privacy, examining during the visit, ${ }^{8,10,12-14}$ service organization factors: using educational materials, informed choice, waiting time, urban facilities, the sanitary condition of the room. $5,8,10,11,13$ However, there is scarce information on client satisfaction with FP services in southern Ethiopia, specifically in the study area.

In Ethiopia, more than one-third (37\%) of women who commence contraception discontinue use within 12 months, according to the Ethiopian Demographic and Health Survey (EDHS) 2016 report. $^{15}$ The Ethiopian government introduced the health sector transformation plan (HSTP) intending to increase the contraceptive prevalence rate (CPR) to $55 \%$ and reduce the unmet need for FP use to $10 \%$ by 2020 , but the progress is slow as EDHS 2019 found CPR to be $41 \%{ }^{16,17}$

Thus, improving client satisfaction with FP services could be one strategy to contribute to the achievement of the goal. Therefore, assessments of client satisfaction are needed to know the current status plan for program improvement. Therefore, this study tried to assess client satisfaction with family planning services and its associated factors at the public health facilities of Tembaro district, Kembata Tembaro zone.

\section{Patients and Methods Study Design and Setting}

A facility-based, cross-sectional study was conducted in Tembaro district, Kembata Tembaro zone, Southern Nations Nationalities and People Region (SNNPR). It is known for its high population density. Mudula, the capital of the district, is located at a distance of 169 kilometers from the regional capital, Hawassa, and 370 kilometers from Addis Ababa. The district, under its total surface area of 135 square kilometers encompasses 19 kebeles (the smallest administrative unit). The total population of the district is close to 140,000 , with the population divided between $50.9 \%$ female and $49.1 \%$ male. The district has 1 primary hospital, 3 functional health centers, and 22 health posts staffed with 122 health workers and 56 health extension workers to serve its population located in the 19 kebeles.

\section{Sample Size Determination and Sampling Procedure}

The sample size was determined by using both single and double population proportion formula. The following assumptions were used to calculate sample size for the first objective: 95\% confidence level (1.96), 5\% margin of error, and proportion (P) of the family planning clients satisfied with service given in a facility-based study in Wonji town which is $56 \%{ }^{13}$ Accordingly, the sample size was calculated by using the formula:

$\mathrm{n}=\left(\mathrm{z}_{(\alpha / 2)}\right)^{2} \mathrm{p}(1-\mathrm{p}) / \mathrm{d}^{2}$ where $\mathrm{n}=$ sample size, $\mathrm{Z}(\alpha / 2)=$ critical value of normal distribution, $\mathrm{P}=$ population proportion, and $\mathrm{d}=$ margin of error. The sample size becomes 411 , including $10 \%$ non-response.

The sample size for the second objective was determined using double population proportion formula with the assumptions of $95 \% \mathrm{CI}, 5 \%$ margin of error, $80 \%$ power, and unexposed to the exposed ratio of $1: 1$ and odds ratio of $3.04^{10}$ and the sample size becomes 274 . The final sample size is therefore 411 .

The study population (n) was further allocated to each of the selected facilities proportional to the size of their client flow. For this allocation, a sampling fraction $(=n / N)$ was used for all the facilities proportionally, making it 
proportional to size. The study participants were consecutively interviewed from each facility until the calculated sample size achieved.

\section{Data Collection Method}

The instrument was adapted from previous works of literature. ${ }^{5,8-12,18-20}$ Data were collected using a validated and pre-tested structured questionnaire. The questionnaire contained the following: socio-demographic factors of the clients, their health service organization experience, reproductive health history, and provider competence from the four public health facilities. Data were collected by four health workers who were briefly trained on the objectives of the study and the tool. To minimize observational bias, the participants were well informed about the risks, benefits, confidentiality, and the right of stopping/rejecting their responses at any time during the interview.

\section{Variables and Measurements}

In this study, client satisfaction (outcome variable) was assessed using fifteen Likert-scaled question items. Each item of the question had 5-points, one denoting " 1 " strongly disagree, two " 2 " disagree, three " 3 " not sure, four " 4 " agree and five " 5 " strongly agree. Finally, the mean was computed, and by classifying to above/equal and below the mean the response was categorized in to "Satisfied (coded as 1)" and "Not-satisfied (coded as 0)", respectively.

The independent variables include socio-demographic factors (age, residence, marital status, educational level, religion, ethnicity, occupation), health facility-related factors (frequency of visit, opening time convenience, privacy maintained during counseling and procedure, cleanliness of the clinic, waiting time and rooms having posters with key messages of family planning), information given and provider-related factors (appointments made for follow-up, clinical staff show respect, providers explain how the method works, providers demonstrate how to use the method, providers describe the possible side-effect, providers describe what to do when a problem occurs and providers describe the possibility of changing the method when there is complication) and other interpersonal characteristics.

\section{Data Management and Analysis}

The pre-coded data were entered into Epi Data version 4.2.0 and exported to SPSS version 25 for analysis. Descriptive statistics were used to present the frequencies, proportion, and summary statistics. Bivariate analysis was carried out to see the association of each independent variable with the client satisfaction with family planning service. Those variables with a p-value of less than 0.25 were included in multivariable logistic regression analysis. Age category, occupation, and received family planning method were excluded from multivariable analysis because p-value $>0.25$. Multivariable logistic regression analysis was carried out to control possible confounders and identify factors independently associated with client satisfaction with family planning service. Finally, variables with a p-value of less than 0.05 in the multivariable logistic regression analysis were considered as significant association with client satisfaction with family planning service. The odds ratio was used to identify the strength of client satisfaction with family planning services.

\section{Ethical Statement}

Before data collection, the ethical clearance was obtained from the institutional review board (IRB) of the College of Health Science and Medicine, Wolaita Sodo University with IRB number CHSM/ERC/43. Participation in the study was on voluntary bases and they were informed about the right not to participate or withdraw at any time. We obtained informed verbal consent from the participants after necessary explanation about the purpose of the study, its benefits, and the outcome and was accepted and approved by the IRB of College of Health Science and Medicine, Wolaita Sodo University, and that this study was conducted following the Declaration of Helsinki.

\section{Result}

\section{Socio-Demographic Characteristics}

We interviewed a total of 407 clients from four family planning service delivery points. The response rate was $99 \%$. Two hundred fifty $(61.4 \%)$ were rural dwellers. More than three-quarters of the respondents, $79 \%$, were repeat clients. The mean age was $27.7+5.2 \mathrm{SD}$ years old with a range between 18 and 44 years. More than half of the participants, 57\%, were between 25 and 34 years old. Most of the respondents, 90\%, were married, and $6.9 \%$ were single, the rest widowed and divorced. More than one-third, 39\%, reported completing primary-level education, and 32\% reported completing high school (Table 1).

\section{Health Facility and Service Providers Related Factors}

The majority of clients, $86.5 \%$, responded that the opening time of the family planning room was convenient to them 
Table I Sociodemographic Characteristics of Respondents, Tembaro, September 2019

\begin{tabular}{|c|c|c|c|}
\hline \multicolumn{2}{|c|}{ Background Characteristics } & \multirow{4}{*}{$\begin{array}{l}\text { Frequency } \\
119 \\
232 \\
56\end{array}$} & \multirow{4}{*}{$\begin{array}{l}\% \\
29.2 \\
57 \\
13.8\end{array}$} \\
\hline Age (in years) & $15-24$ & & \\
\hline & $25-34$ & & \\
\hline & $35-44$ & & \\
\hline \multirow[t]{2}{*}{ Residence } & Rural & 250 & 61.4 \\
\hline & Urban & 157 & 38.6 \\
\hline \multirow[t]{4}{*}{ Marital status } & Single & 28 & 6.9 \\
\hline & Married & 368 & 90.4 \\
\hline & Divorced & 10 & 2.5 \\
\hline & Widowed & 1 & 0.2 \\
\hline \multirow{4}{*}{ Educational level } & No formal education & 82 & 20.1 \\
\hline & Primary & 128 & 39.4 \\
\hline & Secondary & 103 & 31.7 \\
\hline & College and above & 94 & 28.9 \\
\hline \multirow[t]{4}{*}{ Religion } & Protestant & 182 & 44.7 \\
\hline & Orthodox & 119 & 29.2 \\
\hline & Catholic & 63 & 15.5 \\
\hline & Muslim & 42 & 10.3 \\
\hline \multirow[t]{6}{*}{ Ethnicity } & Tembaro & 288 & 71 \\
\hline & Hadiya & 53 & 13 \\
\hline & Kembata & 36 & 9 \\
\hline & Dawuro & 14 & 3 \\
\hline & Wolaita & 8 & 2 \\
\hline & Other & 8 & 2 \\
\hline \multirow[t]{6}{*}{ Occupation } & Housewife & 123 & 30 \\
\hline & Merchant & 26 & 6 \\
\hline & Government employee & 107 & 27 \\
\hline & No occupation & 19 & 5 \\
\hline & Student & 117 & 29 \\
\hline & Others & 14 & 3 \\
\hline \multirow[t]{2}{*}{ Frequency of visit } & New & 84 & 21 \\
\hline & Repeat & 323 & 79 \\
\hline
\end{tabular}

while $89 \%$ agreed on the convenience of working hours for the family planning clinic. On the contrary, $72.2 \%$ of the study participants were not comfortable with the cleanliness of the clinic. In addition to that, $61.2 \%$ of the respondents responded that the family planning waiting room had no posters with a message about family planning. As well, more than half of the respondents, $52 \%$, responded that privacy was ensured during the procedure (Table 2).

Regarding the perceived technical competence of service providers, $71.5 \%$ of the women answered in agreement with whether the provider explained how the method worked. Around $70 \%$ of users said that the provider had demonstrated how to use the method chosen. Almost two-
Table 2 Clients Responses with Aspects of FP Services Organization in Government Health Facilities in Tembaro, September 2019

\begin{tabular}{|l|l|l|}
\hline Clients Response & Frequency & $\%$ \\
\hline $\begin{array}{l}\text { Opening time convenience } \\
\text { Yes }\end{array}$ & 352 & 86.5 \\
No & 55 & 13.5 \\
\hline Working hour convenience & & \\
Yes & 362 & 89 \\
No & 45 & 11 \\
\hline Privacy ensured during the procedure & & \\
Yes & 211 & 51.8 \\
No & 196 & 48.2 \\
\hline Comfortable with the cleanliness of the clinic & & \\
Yes & 113 & 27.8 \\
No & 294 & 72.2 \\
\hline Clinical staff showed respect & & \\
Yes & 317 & 77.9 \\
No & 90 & 22.1 \\
\hline Waiting room has a poster on family planning & & \\
Yes & 158 & 38.8 \\
No & 249 & 61.2 \\
\hline Client waiting time & 131 & 32 \\
Less than 30 minutes & 135 & 33 \\
Greater than one hour & 141 & 35 \\
\hline Follow up card filled with date of appointment & & \\
was given & 354 & 87 \\
Nes & 53 & 13 \\
\hline
\end{tabular}

thirds, $60.4 \%$, of the women said that they had received a description from providers about the possible side effects of the methods. The provider informed about the complications they could expect to experience for $59.7 \%$ of users (Table 3).

\section{The Magnitude of Client Satisfaction on Family Planning}

The overall client satisfaction with family planning services was $46 \%$ [ $95 \% \mathrm{CI}$ : $41 \%-50.8 \%$ ].

\section{Factors Associated with Client}

\section{Satisfaction}

In bivariate analysis, age, residence, educational level of the participants, waiting time, ensuring the family planning room 
Table 3 Perceived Technical Competence of Family Planning Providers, Tembaro. September 2019

\begin{tabular}{|l|l|l|}
\hline Technical Competence & Frequency & $\%$ \\
\hline Provider explained how the method work & & \\
Yes & 291 & 71.5 \\
No & 116 & 28.5 \\
\hline Demonstrate how to use the method & & \\
Yes & 285 & 70 \\
No & 122 & 30 \\
\hline Describe possible side effects & & \\
Yes & 246 & 60.4 \\
No & 161 & 39.6 \\
\hline Describe what to do when a problem occurs & & \\
Yes & 281 & 70.8 \\
No & 119 & 29.2 \\
\hline Describe the possibility of changing method if & & \\
not happy & & \\
Yes & 322 & 79.1 \\
No & 85 & 20.9 \\
\hline Describe follow-up visit & & \\
Yes & 358 & 88 \\
No & 49 & 12 \\
\hline Information regarding complication & & \\
Yes & 164 & 40.3 \\
No & & \\
\hline
\end{tabular}

is indicated with bold lettering, maintaining privacy during the procedure, having family planning room with posters displaying key messages on family planning, having a history of side effects of the methods, having a discussion with husbands about the family planning methods, measuring blood pressure during the visit, measuring weight during the visit, describing how the methods work, clear description of the side effects, and making an appointment for the next visit were factors associated with client satisfaction. The result from multivariable logistic regression was that those clients from the rural residence were three times higher odds to be satisfied with the family planning service as compared to urban residence [AOR $=3.07 ; 95 \%$ CI: $1.10-8.62]$. Clients whose educational level of college and above possessed $78 \%$ fewer odds of satisfaction with the family planning services as compared to those whose educational level was that of primary education $[\mathrm{AOR}=0.22$; 95\% CI: 0.07-0.70]. Clients who waited for less than half an hour had eight times higher odds of being satisfied with services than those who waited for more than an hour [AOR $=7.80$; 95\% CI: 2.50-24.48]. Regarding privacy, clients whose privacy was ensured had seven times higher odds of being satisfied with the family planning services as compared to those who were not treated with privacy $[\mathrm{AOR}=7.16 ; 95 \%$ CI: 2.89-17.69]. Clients who received a clear description of the side effect of the methods had three times higher odds of being satisfied with the family planning services as compared to those who do not get a clear description of the side effects of the method [AOR $=3.14 ; 95 \%$ CI: 1.02-9.76]. Furthermore, clients who received services from facilities that had posters with messages on family planning were nine times more likely to be satisfied with family planning services as compared to those who received services from facilities that did not post posters with messages on family planning $[\mathrm{AOR}=9.00 ; 95 \%$ CI: 3.27-24.75] (Table 4).

\section{Discussion}

The magnitude of client satisfaction with family planning service was found to be $46 \%$ [95\% CI: $41 \%-50.8 \%$ ]. Moreover, residence, educational level, waiting time, maintaining privacy during the procedure, presence of posters with messages on family planning in the waiting room, and getting a clear description of the side-effects of the methods are all factors that are significantly associated with client satisfaction.

The magnitude of client satisfaction with family planning services was found to be $46 \%$. This finding was consistent with studies conducted in Jigijiga (41.7\%), ${ }^{21}$ Wonji $(45 \%)^{13}$ eastern Ethiopia and Congo (42\%). ${ }^{14}$ This finding is lower than studies conducted in Bahirdar $(66.1 \%),{ }^{22}$ Hossana $(75.3 \%),{ }^{10}$ west Shawa $(62.6 \%),{ }^{7}$ countrywide Ethiopia (58.5), ${ }^{11}$ Tanzania (91\%), ${ }^{12}$ Mozambique (86\%), ${ }^{9}$ Bangladesh (75), ${ }^{23}$ and Mexico (80\%). ${ }^{24}$ The probable reasons for the discrepancy among the studies might be due to socio-demographic differences among the different study populations.

The odds of reporting satisfaction is higher among clients from rural residences as compared to clients from urban residences. Literature suggests that the majority of rural dwellers have a low level of knowledge on family planning, and this could affect their level of expectation. ${ }^{25}$ The odds of reporting satisfaction is lower among clients with the educational level of college and higher as compared to clients with a primary level of education. A higher educational level could mean that expectations could be higher because satisfaction can be affected by hope. This finding is a consistent study conducted in Jimma $^{20}$ and Wonji. ${ }^{13}$

The odds of reporting satisfaction were higher among clients who waited less than 30 minutes to receive care as 
Table 4 Factors Associated with Client Satisfaction on Family Planning Services. Tembaro, 2019

\begin{tabular}{|c|c|c|c|c|c|}
\hline \multirow[t]{2}{*}{ Variable } & \multirow[t]{2}{*}{ Category } & \multicolumn{2}{|c|}{ Satisfaction } & \multirow[t]{2}{*}{ UOR $(95 \% \mathrm{Cl})$} & \multirow[t]{2}{*}{ AOR $(95 \% \mathrm{Cl})$} \\
\hline & & Satisfied & $\begin{array}{l}\text { Not- } \\
\text { Satisfied }\end{array}$ & & \\
\hline Residence & $\begin{array}{l}\text { Rural } \\
\text { Urban }\end{array}$ & $\begin{array}{l}108 \\
79\end{array}$ & $\begin{array}{l}142 \\
78\end{array}$ & $\begin{array}{l}0.75(0.50-1.12) \\
\mathrm{I}\end{array}$ & $\begin{array}{l}3.07(1.10-8.62)^{*} \\
1\end{array}$ \\
\hline Age & $\begin{array}{l}18-24 \\
25-34 \\
35^{+}\end{array}$ & $\begin{array}{l}56 \\
99 \\
32\end{array}$ & $\begin{array}{l}63 \\
133 \\
24\end{array}$ & $\begin{array}{l}0.66(0.35-1.26) \\
0.55(0.31-1.00) \\
I\end{array}$ & $\begin{array}{l}0.77(0.16-3.78) \\
0.68(0.16-2.90) \\
\text { I }\end{array}$ \\
\hline Educational level & $\begin{array}{l}\text { Primary } \\
\text { Secondary } \\
\text { College and } \\
\text { above }\end{array}$ & $\begin{array}{l}52 \\
39 \\
65\end{array}$ & $\begin{array}{l}42 \\
64 \\
63\end{array}$ & $\begin{array}{l}\text { I } \\
0.83(0.48-1.42) \\
0.49(0.27-0.87)\end{array}$ & $\begin{array}{l}\text { I } \\
0.41(0.13-1.35) \\
0.22(0.07-0.70)^{*}\end{array}$ \\
\hline Waiting time & $\begin{array}{l}<30 \text { minutes } \\
30 \text { minute- } \mathrm{hr} \\
>1 \mathrm{hr}\end{array}$ & $\begin{array}{l}114 \\
49 \\
24\end{array}$ & $\begin{array}{l}17 \\
86 \\
117\end{array}$ & $\begin{array}{l}32.7(16.7-64) \\
2.77(1.58-4.87) \\
\text { I }\end{array}$ & $\begin{array}{l}7.80(2.48-24.48)^{* *} \\
2.57(0.92-7.15) \\
\text { I }\end{array}$ \\
\hline FP room localized in bold letters & $\begin{array}{l}\text { Yes } \\
\text { No }\end{array}$ & $\begin{array}{l}95 \\
92\end{array}$ & $\begin{array}{l}45 \\
175\end{array}$ & $\begin{array}{l}4.01(2.59-6.20) \\
I\end{array}$ & $\begin{array}{l}2.3 I(0.88-6.10) \\
I\end{array}$ \\
\hline Privacy ensured during the procedure & $\begin{array}{l}\text { Yes } \\
\text { No }\end{array}$ & $\begin{array}{l}161 \\
26\end{array}$ & $\begin{array}{l}50 \\
170\end{array}$ & $\begin{array}{l}2 \mathrm{I}(12.5-35.4) \\
\mathrm{I}\end{array}$ & $\begin{array}{l}7.16(2.89-17.69)^{* *} \\
\text { । }\end{array}$ \\
\hline Room have posters with key messages on FP & $\begin{array}{l}\text { Yes } \\
\text { No }\end{array}$ & $\begin{array}{l}|3| \\
56\end{array}$ & $\begin{array}{l}27 \\
193\end{array}$ & $\begin{array}{l}16.7(10-27.8) \\
1\end{array}$ & $\begin{array}{l}9.00(3.27-24.75)^{* *} \\
1\end{array}$ \\
\hline History of side-effect of the method & $\begin{array}{l}\text { Yes } \\
\text { No }\end{array}$ & $\begin{array}{l}93 \\
94\end{array}$ & $\begin{array}{l}152 \\
67\end{array}$ & $\begin{array}{l}0.43(0.29-0.65) \\
1\end{array}$ & $\begin{array}{l}0.39(0.14-1.09) \\
1\end{array}$ \\
\hline Blood pressure measured during the visit & $\begin{array}{l}\text { Yes } \\
\text { No }\end{array}$ & $\begin{array}{l}110 \\
77\end{array}$ & $\begin{array}{l}22 \\
198\end{array}$ & $\begin{array}{l}\mid 2.8(7.58-2 \mid .8) \\
\mid\end{array}$ & $\begin{array}{l}2.89(0.83-10.07) \\
\mathrm{I}\end{array}$ \\
\hline Weight measured during the visit & $\begin{array}{l}\text { Yes } \\
\text { No }\end{array}$ & $\begin{array}{l}129 \\
58\end{array}$ & $\begin{array}{l}55 \\
165\end{array}$ & $\begin{array}{l}6.67(4.31-10.3) \\
1\end{array}$ & $\begin{array}{l}1.87(0.62-5.66) \\
\mathrm{I}\end{array}$ \\
\hline Discussed about the method with her husband & $\begin{array}{l}\text { Yes } \\
\text { No }\end{array}$ & $\begin{array}{l}148 \\
39\end{array}$ & $\begin{array}{l}146 \\
74\end{array}$ & $\begin{array}{l}1.92(1.22-3.01) \\
1\end{array}$ & $\begin{array}{l}0.43(0.14-1.30) \\
\mathrm{I}\end{array}$ \\
\hline Described how method work & $\begin{array}{l}\text { Yes } \\
\text { No }\end{array}$ & $\begin{array}{l}153 \\
34\end{array}$ & $\begin{array}{l}138 \\
82\end{array}$ & $\begin{array}{l}2.67(1.68-4.24) \\
I\end{array}$ & $\begin{array}{l}0.85(0.29-2.26) \\
\mathrm{I}\end{array}$ \\
\hline Demonstrate how to use the method & $\begin{array}{l}\text { Yes } \\
\text { No }\end{array}$ & $\begin{array}{l}143 \\
44\end{array}$ & $\begin{array}{l}142 \\
78\end{array}$ & $\begin{array}{l}1.78(1.15-2.76) \\
1\end{array}$ & $\begin{array}{l}0.96(0.34-2.66) \\
1\end{array}$ \\
\hline Get description about the side-effect & $\begin{array}{l}\text { Yes } \\
\text { No }\end{array}$ & $\begin{array}{l}146 \\
41\end{array}$ & $\begin{array}{l}100 \\
120\end{array}$ & $\begin{array}{l}4.27(2.76-6.6 I) \\
I\end{array}$ & $\begin{array}{l}3.14(1.02-9.76)^{*} \\
1\end{array}$ \\
\hline $\begin{array}{l}\text { Appointed to come before the next visit if } \\
\text { complication occurs }\end{array}$ & $\begin{array}{l}\text { Yes } \\
\text { No }\end{array}$ & $\begin{array}{l}160 \\
27\end{array}$ & $\begin{array}{l}128 \\
92\end{array}$ & $4.26(2.6 \mathrm{I}-6.93)$ & $\begin{array}{l}2.26(0.59-8.66) \\
\text { । }\end{array}$ \\
\hline
\end{tabular}

Notes: *Significant $\mathrm{p}$-value $<0.05$, * Significant $\mathrm{p}$-value $<0.0001$.

compared with clients who had to wait more than one hour. This evidence is consistent with earlier studies done in Bahirdar, ${ }^{22}$ Hossana, ${ }^{10}$ Wonji, ${ }^{13}$ Jimma, $^{20}$ a countrywide study in Ethiopia, ${ }^{11}$ Nigeria, ${ }^{8}$ and Bangladesh. ${ }^{23}$ This finding suggests that shortening waiting times could increase client satisfaction and improve the quality of family planning services. Additionally, according to the current study, there were higher odds of being satisfied in family planning services when the clients receive services from facilities with posters with key messages on family planning services in their 
waiting room as compared to their counterparts. This could be due that when clients get key messages on the services they are going to receive, it can make them ready to receive the services. The finding also suggests that equipping the service provision room could bust the client satisfaction.

Regarding privacy, in the current study, clients whose privacy was maintained during family planning counseling and procedures were more likely to be satisfied with the family planning service than their counterparts. This is in agreement with a previous study conducted in Hosanna ${ }^{10}$ and Bahirdar. ${ }^{22}$ This evidence was also supported by the earlier study done in Bahirdar. ${ }^{22}$ This implies facilities and providers need to play their role in maintaining privacy during service provision. The odds of reporting satisfaction is higher among clients who get a clear description of the side-effects of the method as compared to their counterparts. This evidence is consistent with study findings from Jigijiga ${ }^{21}$ and a countrywide study in Ethiopia. ${ }^{11}$ The finding implies the counseling on side effects could improve satisfaction and indirectly improve service quality.

\section{Conclusion and Recommendation}

In this study, the overall client satisfaction with family planning service was found to be low in family planning service delivery points, which may have an impact on the family planning service quality and utilization. Moreover, shorter waiting times, maintaining privacy during counseling and procedure (especially important for rural residents), presence of posters with a message on family planning, and receiving a clear description of the sideeffects of the method were factors positively associated with client satisfaction with family planning services. Higher educational level was a factor negatively associated with client satisfaction with family planning services. Therefore, there is a need for specific interventions, namely, shortening waiting time, maintaining privacy during counseling and procedures, equipping service provision rooms with necessary materials, and improving counseling, specifically on the side effects of the family planning methods.

\section{Abbreviations}

CPR, Contraceptive Prevalence Rate; EDHS, Ethiopian Demographic and Health Survey; FP, Family Planning; IRB, Institutional Review Board; SNNPR, Southern Nations, Nationalities, and Peoples' Region.

\section{Data Sharing Statement}

The datasets used and/or analyzed during the current study are available from the corresponding authors on reasonable request.

\section{Acknowledgments}

We want to thank the authorities of Kembata Tembaro Zone Health Department and Tembaro District Health Office. We also want to thank Mudula Primary Hospital, Hodo Health Centre, Debub Ambukuna Health Centre, and Gaecha Health Centre. The study participants, data collectors, and supervisors also deserve our acknowledgment. Dr. Erin Macleod should also be thanked for her support.

\section{Author Contributions}

DW and TL: Designed the study, collected, analyzed, and interpreted the data, and also drafted the manuscript. MM: Participated in the conceptualization of the research, design, analyses, and interpretation of results as well as drafting and review of the manuscript. All authors contributed to data analysis, drafting or revising the article, gave final approval of the version to be published, and agree to be accountable for all aspects of the work.

\section{Disclosure}

The authors declare that they do not have any conflicts of interest regarding any aspect of the article.

\section{References}

1. Bongaarts J, Casterline J. Fertility Transition: is sub-Saharan Africa Different? Popul Dev Rev. 2012;38:153-168. doi:10.1111/j.17284457.2013.00557.x

2. Cleland JBS, Glasier A, Glasier A, et al. Family planning: the unfinished agenda. Lancet. 2006;368(9549):1810-1827. doi:10.1016/ S0140-6736(06)69480-4

3. Technical reference materials family planning. 2013. Available from https://www.mhtf.org/document/technical-reference-materials-familyplanning/.AccessFebruary, 212020.

4. World Family Planning 2017 Highlights. 2017. Available from: https:// www.un.org/en/development/desa/population/publications/pdf/family/ WFP2017_Highlights.pdf. AccessDecember, 102019.

5. Hutchinson PL, Do M, Agha S. Measuring client satisfaction and the quality of family planning services: A comparative analysis of public and private health facilities in Tanzania, Kenya and Ghana. BMC Health Serv Res. 2011;11(1):203. doi:10.1186/1472-6963-11-203

6. Askew I, Brady M. Reviewing the Evidence and Identifying Gaps in Family Planning Research: The Unfinished Agenda to Meet FP2020 Goals. 2013.

7. Birhanu Z, Assefa T., Woldie M, et al. Determinants of satisfaction with health care provider interactions at health centers in Central Ethiopia: a cross sectional study. BMC Health Serv Res. 2010;10:78.

8. Kaoje UA, Oche MO, Isah BA, et al. Determinants of client satisfaction with family planning services in government health facilities in Sokoto, Northern Nigeria. Sahel Med J. 2015;18(1):20. doi:10.4103/ $1118-8561.152154$ 
9. Chavane L, Dgedge M, Bailey P, et al. Assessing women's satisfaction with family planning services in Mozambique. J Fam Plann Reprod Health Care. 2017;43:222-228.

10. Argago T, Hajito K, Kitila S. Client's satisfaction with family planning services and associated factors among family planning users in Hossana Town Public Health Facilities, South Ethiopia: facility-based cross-sectional study. Int J Nurs Midwifery. 2015;7(5):74-83. doi:10.5897/IJNM2015.0163

11. Tessema G, Mahmood MA, Gomersall JS, et al. Client and facility-level determinants of quality of care in family planning services in Ethiopia: multilevel modelling. PLoS One. 2017;12(6): e0179167. doi:10.1371/journal.pone.0179167

12. Bintabara D, Ntwenya J, Maro II, et al. Client satisfaction with family planning services in the area of high unmet need: evidence from Tanzania Service Provision Assessment Survey, 2014-2015. Reprod Health. 2018;15(1). doi:10.1186/s12978-018-0566-8

13. Wakjira B. Assessment of Client Satisfaction on Family Planning Services Utilization in Wonji Hospital, Ethiopia, 2016. JBR J Clin Diagnosis Res. 2017;5:1.

14. Ndziessi G, Bintsene-Mpika G, Bileckot R. User satisfaction with family planning services in government health centers in the Congo. Afr J Reprod Health. 2017;21:70-75.

15. CSACE, I. Ethiopia Demographic and Health Survey 2016. Addis Ababa and Rockville: CSA and ICF; 2016. Available from https:// dhsprogram.com/pubs/pdf/FR328/FR328.pdf. AccessSeptember, 122019.

16. ICF, E.E.M.D. Mini Demographic and Health Survey 2019. Addis Ababa and Rockville: Ethiopian Public Health Institute(EPHI) and DHS Program ICF; 2019. Available from https://dhsprogram.com/ pubs/pdf/PR120/PR120.pdf. Access February, 202020.

17. Admasu KB. Health Sector Transformation Plan 2015/16-2019/20 (2008-2012 Efy). Addis Ababa: The Federal Democratic Republic of Ethiopia Ministry of Health; 2015. Available from https://www.glo balfinancingfacility.org/ethiopia-health-sector-transformation-plan -201516-201920. AccessSeptember 102019.
18. Hidalgo Berutich A, Pedregal Gonzalez M., Barbosa Cortes M, et al. Assessing Patients' Satisfaction on Family Planning Services in a Rural Area. J Community Med Health Care. 2017;2:1014.

19. Saeed R, Ghafoor MO., Sarwar B, et al. Factors affecting customer satisfaction in health care services in Pakistan. J Basic Appl Sci. 2013;3:947.

20. Tafese F, Woldie M, Megerssa B. Quality of family planning services in primary health centers of Jimma zone, Southwest Ethiopia. Ethiop $J$ Health Sci. 2013;23:245.

21. Gebreyesus A. Determinants of client satisfaction with family planning services in public health facilities of Jigjiga town, Eastern Ethiopia. BMC Health Serv Res. 2019;19(618). doi:10.1186/s12913019-4475-5

22. Asrat W, Mekonnen T, Bedimo M. Assessment of women's satisfaction with family planning service at public health facilities in the Northwest Region of Ethiopia: a cross-sectional study. $B M C$ Contraception Reprod Med. 2018;3(1):25. doi:10.1186/s40834-0180079-4

23. Aldana JM, Piechulek H, Al-sabir A. Client satisfaction and quality of health care in rural Bangladesh. Bull World Health Organ. 2001;79:512.

24. Slater A, Estrada F, Suarez-Lopez L, et al. Overall user satisfaction with family planning services and associated quality care factors: a cross-sectional analysis. Reprod Health. 2018;15(1):172. doi:10.1186/s12978-018-0615-3

25. Singh A, Singh KK, Verma P. Knowledge, attitude and practice GAP in family planning usage: an analysis of selected cities of Uttar Pradesh. Contraception Reprod Med. 2016;1(1):p. 20. doi:10.1186/ s40834-016-0031-4
Open Access Journal of Contraception

\section{Publish your work in this journal}

Open Access Journal of Contraception is an international, peerreviewed, open access, online journal, publishing original research, reports, reviews and commentaries on all areas of contraception. In addition to clinical research, demographics and health-related aspects, the journal welcomes new findings in animal and preclinical

\section{Dovepress}

studies relating to understanding the biological mechanisms and practical development of new contraceptive agents. The manuscript management system is completely online and includes a very quick and fair peer-review system. Visit http://www.dovepress.com/testimonials. php to read real quotes from published authors. 